\title{
Presentación Los problemas del objeto de la retórica
}

\author{
Armando Villegas Contreras \\ Editor asociado \\ Centro Interdisciplinario de Investigación en Humanidades \\ Universidad Autónoma del Estado de Morelos \\ armandovic@uaem.mx
}

\section{$\mathrm{L}$}

os artículos que presentamos en este número de Estudios del discurso pueden considerarse una contribución al debate en el ámbito del análisis del discurso político que establece distinciones entre la capacidad semántica del lenguaje y su fuerza social. Estos estudios lo hacen de manera muy particular. Por una lado, hacen esa separación pero luego la recuperan para establecer que la significación organiza también el mundo de la experiencia. Hace ya tiempo que muchos estudios en este ámbito académico pueden considerarse como crítica y recuperación del "signo lingüístico" cuyas primera irrupciones teóricas pueden remontarse a Saussure. En algún momento, la crítica estuvo archiligada al concepto de signo y a su soberanía sobre todo en los estudios del estructuralismo; estos nuevos estudios van más allá y sin renunciar al análisis del funcionamiento del signo, de la diacronía y la sincronía, de las identidades y las diferencias que existen en la lengua, ofrecen un enorme potencial explicativo al agregar las implicaciones que el hacer de la experiencia comporta en usos de significantes y de significados. Este hacer (que es histórico) no refiere ninguna metodología verificable en las 
academias que los historiadores universitarios profesan, ni identificación de una temporalidad que corte los contextos y sus modos de producirse plegándolos a una cientificidad que aparecería como transparente y fácil de constatar en los archivos. A pesar de que es un saber de la historia, el análisis del discurso verifica las concreciones verbales, los acontecimientos, la historia efectiva (Nietzsche) pero concediendo espacio al rigor de la semántica para llegar siempre a conclusiones provisionales sobre una práctica, una institución o una subjetividad. Podríamos decir, es una combinación de semántica y pragmática. De ahí su fuerza explicativa. Las autoras de este número dan lugar a lo anterior, a partir de palabras cuya claridad deconstruyen pueden narrar y organizar el discurso con experiencias que explican lo social y cuestionan algunas evidencias formales sobre la retórica.

Con un solo vuelco en el registro de la escritura, las implicaciones subjetivas y disciplinares pueden verse en problemas. Así, si en un primer momento la convocatoria a este número estuvo ligada a una afirmación, "el objeto de la retórica es el discurso", Ana María Martínez registra algunas consideraciones al poner signos de interrogación en la afirmación que la convocaba. Para ella el problema no es el "objeto de la retórica", sino el cuestionamiento sobre el concepto mismo de "objeto" y puede así desmontar un saber que se construyó (la epistemología) con la soberanía del "sujeto”. El objeto aparece así como el efecto de cierto cartesianismo aún vigente, en las ciencias, en la filosofía, y aun en las investigaciones que afirman superarlo. Ello solo es posible si se recupera, o más bien, si se hace a un lado el análisis dicotómico y se piensa en la fuerza que nos hace ser hablados con esa oposición. Ese análisis se podría visibilizar con lo que la autora llama "Fuerza del discurso".

Ahora bien, siguiendo en la línea, Silvana Rabinovich nos alerta sobre el uso del verbo protestar cuya fuerza teológica encontramos en los juramentos de la academia, o en las organizaciones religiosas. Reverberación de palabras que no dejan de afectar nuestras prácticas. La función aquí del análisis del verbo incluye un movimiento en el que no se retira la teología (que no se opondría al iluminismo, pensemos en los resabios religiosos que ésta palabra también tiene) sino que se la intenta pensar contrahegmónica. Controlar así el usos de ciertas palabras serviría para explicar ciertas resistencias contra los poderes del Estado en México. No lo hace, por cierto, sin audacia argumental, al construir el texto basada en las 
teorías de dos autores que aquí también se producen discursivamente como contrarrevolucionario uno y revolucionario otro: Carl Schmitt y Jacob Taubes.

De igual forma, Alejandra Vitale empodera viejas palabras griegas como èthos y kairós para implicar muy marcadamente discursos políticos en la reciente historia argentina. Según la autora el discurso de la expresidente argentina, en su formulación, en su sentido de la oportunidad, en su forma de enunciarse convoca un aspecto pedagógico que de paso empodera también a las mujeres. El èthos que aquí se sugiere requiere de conocer un aspecto de las teorías de Ernesto Laclau. Ahí se traslada la sabiduría de la retórica a un asunto de organización institucional y de movilización de sectores grandes de población.

No menos importante es el trabajo de Circe Rodríguez. La autora propone la figura del exilio como un componente crítico al discurso de los derechos humanos y del Estado Nacional en su forma ciudadanizante. Rodríguez compromete el análisis de la fuerza del discurso con la descripción de ciertos procedimientos de apropiación de las palabras que tendrían que ver con la retoricidad de la lengua (Paul de Man) pero también con el poder que implica (Foucault).

El número es muy sugerente, invita a reflexionar sobre el objeto que se le ha asignado a la nueva retórica, pero que comparte con la filosofía, la lingüística, la semántica, la teoría literaria. Es decir, el objeto de este número es la problematización misma de un discurso cuyas apropiaciones no pueden darse por sentadas sin que medie una reflexión sobre el poder, lo social y las academias ciegas por tener un campo de influencia privado. Ahí mismo, en esa reflexión sobre la propiedad de las palabras, surge el mismo conflicto por la organización de los social. 